\title{
AC 2009-1918: ASSESSING PEER ATTITUDES AMONG STEM STUDENTS AND THE POTENTIAL EFFECTS ON THE RETENTION OF MINORITIES IN STEM PROGRAMS
}

\section{Fredericka Brown, University of Texas, Tyler}

Dr. Brown currently serves as an Assistant Professor of Mechanical Engineering at The University of Texas at Tyler. Her research interests include bioheat transfer, thermal comfort, and engineering education.

\section{Kristian Trampus, University of Texas, Tyler}

Ms. Trampus currently serves as the Director of the East Texas STEM Center at The University of Texas at Tyler. Her research interests include metacognition, educational technology, the education of historically under-served populations and STEM education.

\section{Michael Odell, University of Texas, Tyler}

Dr. Odell currently serves as the Director of the School of Education and the Cecelia and Sam Roosth Chair in Education. His research interests include Earth Systems, Space Science, Engineering Education, Online Learning, Design, and Integration of Technology into Teaching. 


\title{
Session XXXX
}

\section{Assessing Peer Attitudes Among STEM Students and The Potential Effects on the Retention of Minorities in STEM Programs}

\begin{abstract}
Numerous national policy papers and studies have reported that the continued lack of recruitment and retention in STEM fields among historically under-represented populations has a serious impact on the economic well being of the United States and its citizenry. Much attention has been paid to the attitudes and interests of minority students regarding their desire to pursue postsecondary education in STEM as well as their persistence in these efforts. In addition, various efforts have been made to increase the recruitment and retention of these populations through outreach programs, mentoring, and summer activities. Less attention has been paid to the pervasive attitudes and actions of their peers within the STEM fields and throughout the STEM pipeline and how these attitudes may have a deleterious effect on the retention rate of minorities in STEM programs over time.

Faculty in the College of Engineering and Computer Science in partnership with faculty in the College of Education and Psychology at the University have begun to assess the attitudes and opinions of STEM students about themselves and about their peers with regards to ability and persistence in STEM education and how these attitudes and opinions might affect others in their peer group longitudinally. Students in freshmen engineering courses, senior level high school courses, and middle school science courses have participated in an extensive survey to assess their current status in STEM coursework, intentions regarding their future in STEM education, and their attitudes and opinions about the coursework and participation of their STEM peers.

This paper describes the results of this preliminary survey assessment within and across the selected grade bands and the implications of these results on efforts to refine recruitment and retention among minorities.
\end{abstract}

\section{Introduction}

Engineers Dedicated to a Better Tomorrow identified engineering as an academic field lagging in achieving racial and gender diversity in their graduating baccalaureate classes [1]. It was noted that there was substantial under-representation of blacks and Native Americans in engineering.

According to the annual Survey of the American Freshman, National Norms, for the last two decades about one-third of freshmen entering college planned to study STEM [2]. In 2006, 44.7\% of Asian freshmen, 34\% of Black freshmen, 35.9\% of Hispanic of Mexican/Chicano/Puerto Rican descent freshman, 34.4\% of American Indian freshmen, and 29.5\% of White freshmen reported that they intended to major in STEM [2]. These numbers represent an increasing trend of a diverse demographic composition of students planning to major in STEM. 
The National Science Foundation, Division of Science Resources Statistics, reported that the total number of bachelor's degrees awarded to U.S. citizens and permanent residents in Science and Engineering fields in 2006 was 473,533 [3]. Where 8.3\% of the S\&E students were Black, 7.7\% Hispanic, .7\% American Indian/Alaska Native, 9.3\% Asian/Pacific Islander, and 64.7\% were White. In 1997, the total number of bachelor's degrees awarded to U.S. citizens and permanent residents in Science and Engineering fields was 388,482 [3]. Where $7.7 \%$ were Black, $6.3 \%$ Hispanic, .59\% American Indian/ Alaska Native, 8.4\% Asian/Pacific Islander, and 70.7\% were White. This trend in the increasing minority representation in $\mathrm{S} \& \mathrm{E}$ graduates leads to a major socio-technological change in the United States, a growing diversity of the workforce.

Demographic projections show the traditional pool that supplies today's technological workforce is shrinking, while untraditional pools such as under-represented groups are growing proportionally, making them the new majority. If the United States is to remain competitive and continue to flourish in the competitive global marketplace, it must draw on the talents of all the population. The need for a highly skilled technical labor force, the new majority, and the aging population are several factors that are driving the need for a comprehensive look at changing the culture of science and engineering.

The underutilization of women and minorities in science and engineering is a problem of national priority [4]. Not only is the social equality of minorities and women at stake, the quality of the United States technical labor force is also in danger. One way to increase the technical pool and attract women and minorities to technical careers is to "change the conversation" [5] and focus on promoting understanding of engineering and technology literacy to the public.

Even with increased efforts nationwide to recruit minorities in STEM, there seems to be a missing piece. Research shows that minority attrition in STEM is primarily due to a hostile, isolationist environment [6] due to the attitudes and perceptions of their peers. While numerous studies on minority students and why they fail to achieve degrees in STEM focus on the students' characteristics, less attention is focused on institutional characteristics and peer perceptions. This is the missing piece that will be examined.

Another limiting factor for women and minority students to achieving degrees in STEM fields is their individual perception of their ability to succeed in a given situation, known as self efficacy, influences their thoughts, feelings, motivation, and behavior [7]. Four factors contribute to the development of self efficacy: mastery experiences, vicarious experiences, social persuasion, and physiological states. Vicarious experiences include peer comparisons, social comparisons with others, and the impact of models. The vicarious experience of women and minority students can prove to have a strong effect on their individual self efficacy when they have limited personal experiences in STEM fields [8]. The perceived anxieties and fears about capabilities as indicators of a lack of ability to succeed, physiological states of self-efficacy lead to lower self-confidence.

It is proposed that students' underlying attitudes and perceptions about the engineering field and their peers affect attrition and retention rates. 
Middle school, high school, and college students were surveyed to determine:

- Attitudinal differences among student populations

- Extent to which the attitudes and these factors are correlated with retention and perceived academic performance in STEM

- Extent to which the perceptions STEM students have of student populations affect the climate for that student population

Before effective initiatives can be developed to reduce the high attrition rate of minorities in STEM, a more in-depth understanding of students' underlying attitudes and perceptions of engineering, science, and their peers is warranted.

\section{Procedure}

Students in middle school, high school and college were surveyed regarding their desire to pursue or their persistence in STEM education (degrees) and the factors which influenced their intention to persist. They were also surveyed regarding their opinions about their peers with regards to proficiency in STEM education/fields. The bulk of the survey instrument was taken from the engineering assessment tools of AWE (Assessing Women and Men in Engineering). The survey instrument developed for middle and high school students consisted of questions taken from the engineering and science versions of the pre-college recruiting surveys with questions added regarding peer perception. The survey instrument developed for college students consisted of questions taken from the retention surveys with questions added regarding peer perception.

The anonymous surveys included questions on the following:

- Gender

- Ethnicity

- Opinions of peer proficiency with regards to gender

- Opinions of peer proficiency with regards to ethnicity

- Confidence in own skills to succeed in STEM coursework

- Desire to pursue or persist in STEM education

- Opinions regarding influence of environment on desire to persist (college only)

Other questions on study skills and strategies were also included in the survey but were not included in this study. The questions over peer proficiency and environment were structured as a four-point Lickert scale. The questions on gender and ethnicity were categorical. The questions over confidence were structured as a four-point Lickert. The questions on desire to pursue or persist were multiple choice. The questions over influence on desire to persist were structured as a fourpoint Lickert scale.

Because of the convenience sampling method used, there is to be expected some difference between the response of the middle school, high school and college respondents' desire to pursue or persist in STEM as the middle school students surveyed were in a general science course and both the high school and college students surveyed had self-selected into rigorous STEM centered coursework. In addition, all three campuses surveyed were predominately white. We would suspect that there 
exists the possibility that the responses would be different at campuses with different demographics.

The students' responses were then analyzed using SPSS repeated measures design (mixed method) with three between-subject variables (gender, ethnicity, grade band) and ten within-subject variables (response to opinion questions).

\section{Results}

One hundred and nineteen students were surveyed. Of these, forty eight were in middle school $\left(8^{\text {th }}\right.$ grade), thirty one were in high school $\left(12^{\text {th }}\right.$ grade) and forty were in college (freshmen engineering course). These were convenience samples of two science courses at one Texas middle school, two senior AP physics classes at one Texas high school and one freshmen engineering class at a Texas university.

Table 1. Participants by Demographics and Academic Rank

\begin{tabular}{|l|l|}
\hline Female & 31 \\
\hline Male & 87 \\
\hline African American & 10 \\
\hline Asian & 3 \\
\hline Hispanic & 13 \\
\hline Caucasian & 88 \\
\hline Other & 4 \\
\hline Middle School & 48 \\
\hline High School & 30 \\
\hline College & 40 \\
\hline
\end{tabular}

\section{Opinions regarding proficiency}

There was a significant difference between the male and female response with regard to minority proficiency in STEM. Males were more likely to state that their minority peers were "less than" sufficient in proficiency, while females were more likely to state that their minority peers were "as proficient".

There was also a significant difference in the response to the question regarding male minority proficiency in STEM education. Asians rated their Black peers as "not proficient", Whites rated Blacks as "neutral" in proficiency, and Blacks rated their Black peers "as proficient". Blacks and Hispanics rated their Asian peers as "neutral" in proficiency. Whites "disagreed" that Asians were proficient.

In this comparison, the other notable difference was each group's ratings on the proficiency of females. White males rated their female peers significantly lower in proficiency than the other groups surveyed.

Black males gave the lowest proficiency rating to their Hispanic peers. Asian males gave the lowest proficiency rating to their Black peers. 
There was a significant difference in the opinions of college students and those of middle/high school with regards to peer proficiency. Regarding the opinion that some groups of students were naturally more proficient at STEM and using the same Lickert scale, middle school mean was 1.02, high school mean was 0.9862 , and college student mean was 2.242 . The general consensus here was that middle/high school students "disagree" that certain groups were naturally more proficient and that college age students "agree" that certain groups were naturally more proficient.

\section{Desire to persist in STEM}

Perhaps most significantly, among the students who reported that they would probably not be persisting in engineering (college level only), minorities primarily reported that they were significantly influenced by environment in this decision. This is in contrast to white males who cited their primary significant influence in not persisting in engineering was grades.

\section{Generalizability of results}

While this preliminary study has shown some interesting results it would be unwise to make blanket generalizations about the correlations or causations hinted at here. Pathways for more generalizable results are explored in the section on further study.

\section{Implications}

Numerous studies have been completed and position papers written on minority recruitment and retention in STEM education and STEM fields and how to improve it. In addition, there have even been studies and policy papers completed on how to market STEM, specifically engineering, to the general public. Most of our efforts have been on how to bolster the interest and confidence of minorities in STEM.

What we have not addressed with as much fervor however, is how a potentially inimical environment affects the retention of students recruited to STEM. It seems logical that this is the approach that researchers have taken overall as it would seem much easier to change the attitudes and perceptions of a sub-group than the larger culture. In other words, we create the desire to pursue STEM education among minorities, we give them the mental tools to succeed in STEM education, but when they arrive in our halls they may be met with an unwelcoming environment and the negative attitudes of their peers.

While our efforts to inspire interest and confidence in STEM education and careers among minorities are noble and necessary, it is not the whole picture. It seems that it would increase the efficacy of our model to address the whole picture including the attitudes of the group which dominates STEM fields. Most cultures are slow to change and engineering and STEM should be thought of as a culture, with gatekeepers and its own particular code. Given the declining enrollment and retention of American students in STEM education and the consequent effect this

will eventually have on the American STEM workforce, it would seem that it is time for a cultural change. 


\section{Suggestions for Further Study}

As mentioned previously, the samples for this study were convenience samples and consisted of one middle school teacher's students (two classes), one high school teacher's students (two classes) and one college faculty's students (one class). It would be important to replicate this study or one similar with other faculty classes sampled as there may be an effect of the particular faculty rather than a trend generalizable to the larger population. In addition, it would be important to pull samples from a targeted middle school (math/science magnet) to more closely align it with the selfselected nature of the AP high school class and the college engineering class samples. Concomitantly, it would be important to also sample the general high school population as well as the general college population to ascertain whether or not these opinions differed from those of the more specialized classes, namely AP physics and freshmen engineering. Larger sample sizes would be beneficial. Given the time and resources, a qualitative study using focus groups would allow for more open ended question and help to define the most relevant and powerful areas of potential correlation/causation.

Additionally, an ethnographic study focusing on the "cultures" of engineering, specifically, and STEM, in general, would be helpful to provide a more clear lens in which to view ourselves and our blind spots with regards to attitudes and perceptions within our ranks.

\section{References}

1. Industrial Engineering, Engineering lags in graduate diversity. Industrial Engineer, Vol. 38 (October 2006), Issue 10, p. 16.

2. National Science Foundation, Science and Engineering Indicators 2008, Arlington, VA: Available on the internet < http://www.nsf.gov/statistics/seind08/start.htm>.

3. National Science Foundation, Division of Science Resources Statistics, Special Tabulations of U.S. Department of Education, National Center for Education Statistics, Integrated

Postsecondary Education Data System, Completions Survey, 1997 - 2006: Available on the internet <http://www.nsf.gov/statistics/wmpd/degrees.cfm\#bachelor $>$.

4. Leslie, LL., McClure, G.T., and Oaxaca, R.L., "Women and Minorities in Science and Engineering: A Life Sequence Analysis," The Journal of Higher Education, Vol. 69, No. 3 (May - June 1998), pp. 239-276

5. National Academy of Sciences, "Changing the Conversation: Messages for Improving Public Understanding of Engineering," <http://books.nap.edu/catalog/12187.html>.

6. Wilson, R., "Barriers to Minority Success in College Science, Mathematics, and Engineering Programs," In G. Campbell, C. Morrison, and R. Denes (Eds.). Access Denied: Race, Ethnicity, and the Scientific Enterprise, (pp. 193 - 206), 2000, Oxford, OH: Oxford Press.

7. Bandura, A., Self-efficacy: The exercise of control. New York: Freeman.

8. Pajares, F., Current directions in self-efficacy research. In M. Maehr and P.R. Pintrich (Eds.). Advances in Motivation and Achievement, Volume 10, (pp. 1-49). Greenwich, CT: JAI Press. 